\title{
LETTERS
}

\section{July Spike in Fatal Medication Errors}

To the Editors:-I read with interest the well-done and thoughtful study by Phillips and Barker, A July Spike in Fatal Medication Errors: A Possible Effect of New Medical Residents ${ }^{1}$. Medical care in general and knowledge of medications in particular are becoming increasingly complex and require years of training and experience to gain proficiency, so the authors' conclusions are both logical and plausible.

I would like to propose an additional explanation for why fatal medication errors are increased every July compared with other months, at least in the inpatient setting. Rather than being mostly attributable to the inexperience of new medical residents, the untoward outcomes may instead be related to poor teamwork and coordination between the residents and the hospital staff, including the attending physicians, nurses, and pharmacists. At institutions such as ours, where medicine residents may have their first hospital rotation in July, August, or later, the errors would seem to be equally likely in any of these months if the residents were the primary cause.

If the study data could be further analyzed according to the "first hospital experience" of the residents, this may help clarify if the July Spike is more of a resident or a systems phenomenon. If there is indeed a systems problem, then

Published online October 15, 2010 medical schools may need to place a greater emphasis on systems-based practice as emphasized in the ACGME's guidelines $^{2}$, and teaching hospitals may need to formally "gear up" for the new residents before July. In the meantime, I fully agree with the recommendations of the authors, including increased resident supervision and more education about medication safety.

A. Scott Keller, MD, Mayo Clinic, 200 1st Street SW, Rochester, MN 55905, USA (e-mail: Keller.scott@mayo.edu).

\section{REFERENCES}

1. Phillips DP, Barker GEC. A July spike in fatal medication errors: a possible effect of new medical residents. J Gen Intern Med. 2010;25 (8):774-9.

2. http://www.acgme.org/acWebsite/downloads/RRC_progReq/140_ internal_medicine_07012009.pdf Accessed July 11, 2010.

$\mathrm{J}$ Gen Intern Med 26(1):10

DOI: $10.1007 /$ s11606-010-1532-5

(C) Society of General Internal Medicine 2010 